The current processes of recovery of post-infarction and post-stroke patients in the context of the establishment of the institution of family doctors and insurance medicine are considered. It was proposed to introduce modules for automation of recovery devices (MARD) to ensure procedures, quality of life and reduce labor costs during the period of long-term recovery. The forms of presentation of the model of the integral indicator are substantiated, which, in accordance with the requirements of the Ministry of Health, assesses the generalized indicator of the patient's statement (GIPS), the quality of medical services and increases the efficiency of data compression. A consistent application of two Euclidean norms is proposed, which leads indicators of dissimilar physical nature to a limited metric space. The relationship between the lower and upper bounds of the GIPS, the error, the width of the sliding window, and the values of the derivatives was established on the basis of the Taylor series expansion, geometric inequality and limited space. The model for evaluating the GIPS as a lower bound and the method for generating information about its properties are substantiated.

A three-level comparator is applied and an vector-indicator (VI) is introduced as an informational addition to the time series. Additional capabilities for intelligent analysis are demonstrated. The model of GIPS through VI is presented. The examples of VI values are used to demonstrate its applicability to the intelligent analysis of the recovery process. Openness, accessibility, transparency of GIPS and VI as tools of KIT is implemented by the princes of public administration (PA) by reducing it to quantitative control and comparison if there are quantitative and qualitative indicators in the list. VI, sliding windows, as PA and KIT tools in software (SW) for a diagnostic conclusion and correction of the course of procedures, are numerically investigated. It is demonstrated on examples of a numerical experiment with software how the combined application of the method for calculating the GIPS and VI effectively affects the compression ratio, increasing it to $60-75 \%$

Keywords: automation module, integral indicator, vector-indicator, lossless compression, recovery devices, public administration
UDC [519.87:519.853]: 35.072.6: 615.8: 681.5

DOI: $10.15587 / 1729-4061.2021 .239288$

\section{METHODS AND TOOLS OF FORMATION OF GENERAL INDEXES FOR AUTOMATION OF DEVICES IN REHABILITATIVE MEDICINE FOR POST- STROKE PATIENTS}

\author{
Alexandr Trunov \\ Corresponding author \\ Doctor of Technical Science, Professor \\ Department of Automation and \\ Computer-integrated Technologies* \\ E-mail: trunovalexandr@gmail.com \\ Volod y m y r B e g y t si a
}

Doctor of Science in Public Administration, Professor

Department of Local Self-Government

and Regional Development*

Gennady Gryshchenko

Candidate of Medical Sciences, Associate Professor,

Director of Institute

Medical Institute*

Viktor Ziuzin

Doctor of Medical Sciences, Professor,

Head of Department

Department of Hygiene, Social Medicine, Public Health and

Medical Informatics*

Vitali Koshovyi

Senior Lecturer

Department of Intelligent Information Systems*

*Petro Mohyla Black Sea National University

68 Desantnykiv str., 10, Mykolaiv, Ukraine, 54000
Received date 28.06.2021 Accepted date 17.08.2021 Published date 31.08.2021
How to Cite: Trunov, A., Beglytsia, V., Grishchenko, G., Zyuzin, V., Koshovyi, V. (2021). Methods and tools of formation of general indexes for automation of devices in rehabilitative medicine for post-stroke patients. Eastern-European Journal of Enterprise Technologies, 4 (2 (112)), 35-46. doi: https://doi.org/10.15587/1729-4061.2021.239288

\section{Introduction}

Rehabilitation recovery of post-infarction and poststroke patients is carried out under the conditions of painstaking and careful diagnostic observation and long-term rehabilitation procedures [1]. In this regard, the quality of life during the period of long-term recovery of post-infarction, post-stroke patients in the conditions of remote reha- bilitation is becoming one of the directions of development of restorative medicine [2]. Setting goals and organizing the recovery process requires researchers, administrators, and clinicians to focus on developing specific modules. They include sensors of force, touch, sound and optical converters of devices for restorative therapy, which restores independence and improves the patient's quality of life [3]. At the same time, the first attempts to create innovative recovery devices 
show that a significant part of the labor costs in the recovery process falls on the collection, analysis, compression and logging of data [4]. Data transmission, representing the correction of prescriptions and the course of recovery procedures, is carried out through the use of radio channels and cloud and network technologies. Especially the problem of security is exacerbated in the conditions of permanent changes inherent in the current state of development of society. The scientifically grounded establishment of the institution of family doctors and insurance medicine [5], together with the introduction of the achievements of computer-integrated technologies in the implementation of the principles of public administration (PA), can change the essence of recovery medicine. One of the most important tasks of the health care system, especially the rural population at the present stage of development, is to find the optimal balance of the processes of specialization, integration and automation [6]. Scientific research is going around the idea of splitting and stimulating muscle contractions, according to tension, edema, dystonia, to restore the motor skills of the fingers and toes. The study of the types of communication signals between a patient with problems that have arisen as a result of the disease, and modules of the automation of the recovery devices (MARD) demonstrates significant amounts of information, the transmission of which becomes problematic [7]. The implementation of ideas of information-lossless exchange presupposes the availability of effective algorithmic and software tools for monitoring, compression and diagnostics. Models of prototypes of automated systems (AS) for post-treatment recovery in conditions of remote rehabilitation, which make it possible to limit the range of access to the patient, are acquiring significant scientific significance. It is expected that in terms of their functions, the level of intellectualization, they will make the rehabilitation therapy of post-infarction, post-stroke patients more effective.

Evidence-based PA methods will play a special role for the effective organization of the functioning of remote medical recovery and the work of doctors and administrators of insurance medicine. They are complemented by innovative tools for automating management processes. In the structure of the patient - family doctor - MARD for collecting parameters of the patient's condition and recovery procedures, the need to implement the principles of openness, accessibility, information readiness, and is the embodiment of the PA principles. The effectiveness of their implementation, as the basic principles and tools of the PA, also determine the software for collection, primary processing, transmission and storage of monitoring data using networks, cloud services and network servers, which will create conditions for transparency, availability and security.

In this regard, the search for the scientific foundations of the formation of a model of compact representation of the data stream as a single integral indicator, the formation of a collection method, the choice of the language and the compression and transmission algorithm is relevant for the creation of a remote recovery MARD. The practical result of these studies will be a reduction in personnel labor and the integration of various devices into a single speaker. Functions such as ensuring openness, transparency and accessibility at any moment, which is regulated by administrative law, as well as the presence of developed software libraries, reflection and communication services, are able to implement the PA principles to the designated sphere of society.

\section{Literature review and problem statement}

The construction and application of MARD in medicine take place in the form of information and recovery systems. The latter are designed primarily as securing the rights and obligations of persons who are provided with rehabilitation assistance [1].

However, control parameters are selected on the basis of indicators, differ for each of the branches of recovery and separately for post-infarction or post-stroke patients [2]. The problem of the designer is that their list is determined by the standards of the Ministry of Health [3]. This list does not coincide with the list of necessary objective, metrologically substantiated indicators required to control the quality of medical care [4]. In this regard, the number of types of parameters depends on the type of rehabilitation recovery and on the structure of the equipment used and the institution providing medical care. In addition, according to the form of presentation, the parameters should be divided into two more types: quantitative and qualitative. In work [8], it is shown that the multifactorial nature of interaction and an unlimited number of factors characterize medical diagnostics and rehabilitation recovery as one of the types of a complex biological-socio-economic process. The process of recovery and assessment of the socio-economic determinants of health is rapidly volatile and requires the use of intelligent information systems to build a diagnosis and restorative prescription and is rapidly volatile [9].

Medical and sociological information in the new conditions acts as a management tool, including the quality of medical care and is subject to audit [10]. This is also evidenced by the data of publications, which demonstrate the effectiveness of the strategy of medical diagnostics based on psychologically functional models of diseases [11]. However, one of the disadvantages of such systems is the complicated process of explaining solutions [11]. The latter, in the context of the need for transparency of information, significantly hinders the development and implementation of MARDs and is one of the problems at the stage of their design.

The processing of time series, which represent a set of parameters of medical information, also requires a quick and highly informative analysis of the entire set of data types and the selection of pathological conditions and expert evaluation of the data [12]. To solve this class of problems, the Bayesian approach, an algorithm for finding association rules, an inference algorithm, cluster analysis methods, models of artificial neural or special recurrent networks, etc. are used. [13]. The peculiarity of the latter lies in the functional addition of the synaptic node memory, a three-level comparator and algebraic operations of summation, multiplication and division [13]. The need to analyze the results of a certain list of parameters of the patient's condition as a process becomes a quantitative-logical-cognitive process is proposed to be implemented in combined systems of rehabilitation recovery [13]. However, the size of the amount of information to be collected, primary processing, storage and analysis is the main obstacle [14]. In publications devoted to the creation and practical application of computer monitoring and recovery systems, devices based on several microcontrollers are increasingly being proposed [15]. So, for example, in work [15] the task of measuring the parameters of the object state and synthesis of the control parameter is provided for 5 analog inputs. They provide the connection of 
unified sensors. In addition, the system contains 7 discrete outputs for connecting the power section of the control system. Each discrete output has logic buffers, which are triggers. Logic buffers keep logic levels on control lines. This approach provides a reduction in power consumption due to the existing possibility of switching the main controller to the minimum power consumption mode. In case of emergency mode in any of the lines, an auxiliary microcontroller is connected [13, 15]. In the case of connecting several controllers, functions are distributed between them, which can be redistributed if necessary [16]. Such systems additionally carry out analysis of control lines, data reception/transmission processes, control of consumed energy. The microcontroller is fundamentally capable of additionally identifying a malfunction, transmitting a message to a centralized data processing point. Also, turn on the audible alarm. Thus, the system is designed to be capable of self-diagnosis and self-expression failure. The organization of communication between the MARD unit with a radio module or a GSM modem is supposed to be through communication interfaces and ensures operation as part of a network [16].

However, the complexity of the organization of the human body makes it difficult to formalize.

However, the complexity of the organization of the human body complicates the formalization of methods for analyzing medical data and limits their implementation. Existing scientific studies using statistical methods generalize and supplement the results of collecting and processing information about the patient's condition [11]. The processing of time series of parameters of the patient's condition according to the list of the Ministry of Health standard determines the parameters of the recovery procedure and their adjustment according to the dynamics of the course of the procedures. In [17], it is demonstrated how the need to define a unified description algorithm with a single indicator successfully implements the task of transparency and simplicity of presentation of multifactor information. However, the need to determine the patient's condition requires the presentation of information in an appropriate structured description of the dynamics of characteristics. Moreover, in the majority, its flows are large in volume and contain qualitative features. For example, the presence of pain, fever, skin color, assessing the patient's condition subjectively. The processing of parameters of the patient's state as input signals that affect the results of the output, determine the information addition in its description of data on internal states. Based on this, the model of the treatment decision support system can be presented based on the concept of the theory of the Mealy automaton. The latter confirms the existence of the function of output signals and depends on a variety of system states and input signals - parameters of the patient's state. As in other monitoring devices, data gaps still remain a significant problem [18]. In [18], algorithms for eliminating gaps are presented and investigated. However, the proposed methods do not exclude an error, and the method of accelerating the process of data loss recovery, proposed [19], concerns only one parameter and does not apply to multiparameter time series. The article offers an understandable and maximally concise representation of the dynamics of the flow of procedures and work with it, introduces adaptive user interfaces of the software analysis system [20]. Despite the tools for improving software and interfaces during implementation, the proposed adaptation does not always give the desired results [21]. Comparative structural-parametric identification of models creates additional opportunities for working with combined quantitative and verbal indicators. In addition, in the absence of data or paramedical assessments, the practice of its application requires a justification of the method of combining them [22]. An example of a compact presentation of information includes the results of comparative processing, the results of work [23]. However, even in this case, the presentation of color images of video frames was seduced to the level of practical implementation in the algorithms for automatic diagnosis of modules of diagnostic automation devices [23].

The formation of MARD applications and their quality assurance is determined by the capabilities of the language and models, methods and algorithms that have been chosen [24]. As of now, the $C \#$ programming language is one of the most powerful languages in the IT industry, developing rapidly. A wide variety of programs are written in $\mathrm{C \#}$ : from small desktop programs to help systems that serve millions of users every day. When they say C\#, they often mean technologies of the .NET platform (Windows Forms, WPF, ASP. NET, Xamarin). The C\# language was created specifically to work with the .NET framework, but the concept of .NET itself is somewhat broader. The .NET framework provides a powerful framework for building applications. The combination of these examples of the advantages and objectives of quality management of medical care in a health care institution determines the expectations of success in the creation of MARD applications [25].

Thus, the unsolved problems include the creation of models for the integral assessment of the patient's condition and the transparent presentation of data on the course of recovery procedures. In addition, the task of simultaneously assessing systems of regulated quantitative and qualitative indicators of health status according to the standards of the Ministry of Health and paramedical assessments is reduced to assessing a list of four types of data. The third unsolved problem is the problem of developing a method of cognitive-comparative analysis of data flow and their lossless compression. Its solution will open up opportunities for an interdisciplinary team of scientists, the Faculty of Computer Science and the Medical Institute and the Institute of Public Administration to develop automated recovery systems in the context of the emergence of family medicine.

\section{The aim and objectives of research}

The aim of research is to substantiate the forms of presentation of the model of the integral indicator, which meets the requirements of the Ministry of Health according to the list and is suitable to increase the efficiency of data compression in the MARD of post-infarction and post-stroke patients in accordance with the principles of PA and to supplement the list of types of indicators, regardless of physical characteristics and quantity.

To achieve the aim, the following objectives were set:

- form a list of types of parameters of the generalized indicator of the patient's statement (GIPS), quality of medical services (quantitative and qualitative) and determine the relationship between the volume, frequency of measurements, time properties and the value of derivatives, indicate the limits of permissible fluctuations in the values of their values;

- form a model for assessing a set of indicators, regulated by the Ministry of Health, and a method of complementing 
quantitative and qualitative indicators for MARD post-infarction, post-stroke patients in accordance with the PA principles, which are implemented in practice due to their tools;

- investigate the applicability of the three-level vector-indicator for informational supplement of the time series of equally parametric monitoring of the state of post-infarction, post-stroke patients and MARD;

- investigate the applicability of the PA principles, which are implemented in practice because of their tools, including in the monitoring software for a diagnostic conclusion and correction of the course of procedures.

\section{Materials and methods of research of the form of presentation of the model of integral assessment of indicators according to the requirements of the Ministry of Health and the list}

The basis for the creation of MARDs for post-infarction, post-stroke patients was based on the current requirements of the Ministry of Health, regulating indicators and methods for measuring them for these types of diseases. It was also assigned that the idea of creating modules that automate wireless patient recovery devices in the individual conditions of remote rehabilitation is implemented by conducting remotely controlled procedures. So it was assumed that the quality of wireless communication of all subjects and structural elements of the system is ensured. This type of communication provides two-level authentication of the patient and the device and self-diagnosis of their state parameters. Increased access and use times are achieved through continuous monitoring and recording of parameters of the patient's condition and the course of procedures. The working hypothesis is: duplication of types of interaction with patients, measurement and diagnostic channels is guaranteed to provide a complete list of parameters for analysis. The introduction of a system of support and decision-making in the course of retraining cognitive skills according to recommendations and with reference parameters complements the meaningfulness of the communicative exchange of recovery procedures. In case of deviation of the state parameters during pre-procedural testing, the deviation is recorded and a request for further doctor's prescription is made, and the monitoring and blocking modules are activated. In case of receipt from the dispatch center of instructions regarding blocking of the damaged functional module or its complete shutdown, the latter is carried out in the prescribed sequence in automatic mode by the components of the wireless networks.

It goes without saying that the formation of a method of generalization, assessment, and the proposal of PA instruments alone will not solve the problem of automating devices for family restorative medicine in post-infarction, post-stroke patients. However, it forms the preconditions for the implementation of innovative technologies for remote recovery in conditions of increased comfort.

The main requirement for the design of the MARD is to ensure information completeness and compression of information flows for monitoring the patient's condition in the structure of the patient - family doctor - insurance company - MARD for collecting parameters of the patient's condition and prognosis. The implementation of the requirement of openness, accessibility, informational readiness as the basic principles of PA and documenting the protocol of the course of recovery procedures and the state of devices im- plements and regulates the requirements of evidence-based medicine and administrative law in the mutual relations of subjects of recovery and administration. The latter is regulated by documents that control the quality of medical services [2-4]. Based on the foregoing, the following provisions were proposed to formulate the requirements for the terms of reference for the MARD design:

- firstly, provide the option of changing the list and editing the time parameters for controlling the sets of indicators and parameters that regulate the Ministry of Health according to the recovery method;

- secondly, provide the option of entering additional indicators and parameters, regulated by the requirements for monitoring the quality of medical services and the state of equipment;

- thirdly, to ensure the input of para-medical indicators and other quality indicators, if necessary.

Thus, the set of specific indicators and parameters are summarized in a list of types of indicators, the number and list of which are established according to the requirements of the Ministry of Health for this type of recovery disease and additional indicators. A variety of physical meaning of quantities, ranges of values and ranges of change is an inherent feature that characterizes many indicators and parameters. Another working hypothesis was put forward: there is a continuous set of real numbers, a limited range of metric space, which reflects the full set of indicators and parameters. The generalized object of physiotherapy, which was considered, is characterized by $K$ indicators, which are formed on the basis of monitoring data on time series. For clarity of perception of the idea of presentation, it was assumed that the indicators characterize pressure, pulse, motor activity and self-awareness, etc. as prescribed by the Ministry of Health. To implement the idea of bringing the parameters of physiological-biological systems to a single space, the indicators were normalized. The choice of the norm was carried out on the basis of the same estimates of the upper and lower pressure, pulse and linguistic assessments of self-awareness and other paramedical indicators. The heterogeneity of the content of such indicators of time series, which are selected as a base [1-4], is also taken into account: pressure, pressure difference, pulse. In connection with the above, for each $i$-th time series, its own value of the Euclidean norm was chosen $\left|X_{i}\right|_{\max }$. This is the first normalization provided the reduction of all quantities to a set of dimensionless numbers. However, taking the maximum value of the modulus in the interval of the domain $\left|X_{i}\right|_{\max }$ of the norm, it should be borne in mind that it must be redefined at each change of the sampling interval and at the transition from one factor to another. Of course, the latter is a significant drawback, but it is this norm that provides high sensitivity to local changes in factors [17]. In addition, for the full use of the limited range of a single space for representing indicators, the second one with a new Euclidean norm is consistently carried out according to the first normalization:

$$
\bar{X}_{i}=\frac{X_{i} /\left|X_{i}\right|_{\max }-\left.\left|X_{i \min } /\right| X_{i}\right|_{\max }}{1-\left|X_{i}\right|_{\min } /\left|X_{i}\right|_{\max }} .
$$

Further, a notation was introduced for the general integral indicator of GIS. Its role can also be denoted as a synonym under the name "general performance index", for example, the ISO 37001:2016 standard. It is further stated that the GIS indicator and $X_{i}$ indicators are continuous val- 
ues (the upper bar in the designated norms was conventionally omitted here and hereinafter).

The method is substantiated, which made it possible to find a function that establishes a relationship between the integral GIS indicator and the normalized, dimensionless indicators. These, for example, include: pulse $-X_{1}$; pressure behind the peak $X_{2}$; lower pressure level $-X_{3}$; temperature $-X_{4}$. For this, the sought function is denoted as follows: $G I S=f\left(X_{1}\right.$, $\left.X_{2}, X_{3}, X_{4}\right)$ and a system of assumptions formulated in the form of postulates is chosen. The main statements of the postulates are: at zero pulse - its GIS is zero; at zero pressure, the GIPS is also zero; in conditions when simultaneously each of the factors is equal to zero, the GIS is equal to zero.

Based on the statements about the continuity of the GIS, it is expanded into a Maclaurin series, which is presented in a linear approximation:

$$
\begin{aligned}
& G I S=\left.\sum_{i}^{N} \frac{\partial G I S}{\partial X_{i}}\right|_{x_{i}=0} \Delta X_{i}=\left.\sum_{i}^{N} \frac{\partial G I S}{\partial X_{i}}\right|_{x_{i}=0} X_{i}=C \sum_{i}^{N} \delta_{i} X_{i} ; \\
& C=\left(\left.\sum_{i}^{N} \frac{\partial G I S}{\partial X_{i}}\right|_{x_{i}=0}\right) ; \delta_{i}=\left.C^{-1} \frac{\partial G I S}{\partial X_{i}}\right|_{x_{i}=0} .
\end{aligned}
$$

In the latter, it is taken into account that after double rationing, the interval for determining all indicators is the only one $X_{i} \in[0,1]$. The specified Maclaurin expansion (2), as a sum in accordance with the properties of geometric inequality, estimates the GIS lower bound:

$$
G I S=C \sum_{i}^{N} \delta_{i} X_{i} \geq C \prod_{i=1}^{N}\left(X_{i}\right)^{\delta_{i}} .
$$

Evaluating the possible options for the dependence of each of the list of types of indicators on the parameters, it was found that the influence of various factors is uneven. The weight coefficients that determine it acquire both positive and negative values. The upper limit of the smallest GIS value was estimated using geometric inequality (3), which is modified by introducing the moduli of the values:

$$
\begin{aligned}
& \left(\left|X_{1}\right|+\left|X_{2}\right|+\left|X_{3}\right|+\left|X_{4}\right|\right) \geq \\
& \geq\left(\frac{\left|X_{1}\right|}{k_{1}}\right)^{k_{1}}\left(\frac{\left|X_{2}\right|}{k_{2}}\right)^{k_{2}}\left(\frac{\left|X_{3}\right|}{k_{3}}\right)^{k_{3}}\left(\frac{\left|X_{4}\right|}{k_{4}}\right)^{k_{4}} .
\end{aligned}
$$

The limited range of values of the unified metric space of parameters and indicators makes it possible to obtain an expression for the upper and GIS lower boundaries, taking into account the introduced designations and properties of the power function:

$$
\left|X_{1}\right|\left|X_{2}\right|\left|X_{3}\right|\left|X_{4}\right|_{\min } \leq G I S \leq\left|4 X_{1} X_{2} X_{3} X_{4}\right|_{\max } .
$$

Thus, on the basis of a consistently applied set of norms, for various variants of weight coefficients, it is reasonable to estimate the upper and lower bounds of the general GIS index (2) according to expressions (3), (4) and (5).

Such a wide range of expressions and meanings prefers pessimistic evaluation - the lower bound, since it gives a single expression and one meaning. In the future, the estimate of the lower bound according to (5) should be used as an estimate of the general GIS performance index.

\section{Results of the study of the model, methods and tools for the automation of devices for the recovery of post- infarction and post-stroke patients.}

\section{1. Determination of the list of types of parameters} of the patient's condition to be measured

The work considered the structure of interacting subjects: a patient, a family doctor, hospitals, insurance companies and MARD (conditionally referred to the class of subjects) for collecting parameters of the patient's condition, network data transmission facilities, servers of the corporate medical network and medical databases.

It was assumed that for the creation of such a module, there are definitions of Ministry of Health, types of indicators and methods of their measurement. Let's also assume that the idea of creating modules that automate wireless devices for the recovery of post-infarction, post-stroke patients in the individual conditions of remote rehabilitation is implemented by conducting remotely controlled procedures. Undoubtedly, it is based on the hypothesis of the feasibility of wireless communication of all elements under the conditions of two-level authentication of the patient and the device and self-diagnosis of their state parameters. Increased access and use times are achieved through continuous monitoring and recording of parameters of the patient's condition and the course of procedures. Another working hypothesis is: duplication of types of interaction with patients, measurement and diagnostic channels. The introduction of a system of support and decision-making in the course of retraining cognitive skills according to recommendations and with reference parameters complements the meaningfulness of the communicative exchange of recovery procedures. In case of deviation of the state parameters during pre-procedural testing, the deviation is recorded and a request for further doctor's prescription is made, and the monitoring and blocking modules are activated. In case of receipt from the dispatch center of instructions regarding blocking of the damaged functional module or its complete shutdown, the latter is carried out in the prescribed sequence in automatic mode by the components of the wireless networks.

An innovative feature of the expected development result was to be a comprehensive implementation of methods that represent an analytical express assessment of complex processes using the GIPS model. The latter allows to quickly block the rehabilitation processes in the event of a predicted hazard and record the full set of assessments of signs and analysis parameters. The development and application of sensors that measure the force of touch, compression and stretching and the speed of movement, the degree of blood circulation in the muscle tissue will provide feedback. The development of intelligent sensors containing the cognitive component of analyzing the actions of patients during procedures, presents a picture of recovery, is recorded in accordance with the requirements of administrative law and evidence-based medicine. It is this quantitative and qualitative information that is the necessary information necessary for both the family doctor and the administration of the drug institution, the patient and the insurance company. Information about GIPS, and, if necessary, expanded indicators according to the list of the Ministry of Health, is provided upon request to all subjects of the recovery process. In the form of a model of the lower limit, it forms a tool for medical and legal assessment by all subjects of administrative law and process, and ensures the protection of their rights in ac- 
cordance with the PA principles. The indicators of the GIPS integrated assessment, as transparent, understandable and available for quantitative comparison, are convenient tools that implement the PA mechanisms. The latter, based on the protocols of interaction of the human-machine interface, will make it possible to adjust the individual set of procedures based on a comparison of the actual and predicted recovery. The innovativeness of the proposed sensors should consist in the simultaneous use of quantitative and qualitative indicators to be presented as a single generalized indicator of GIPS, which increases the monitoring efficiency of data processing and management commands by a family doctor by reviewing a reduced amount of information. This approach will allow solving a number of technical problems when monitoring the process and MARD, post-infarction, poststroke patients. The list and number of these parameters has been determined, since the method is set in accordance with the Ministry of Health standard. However, in order to implement the cognitive component in the analysis of actions and results during the course of procedures and self-diagnostics of equipment, the number of parameters is expanding. In addition, the reason for changes or expansion of their number is also a change in the recovery method when changing patients from different groups of diseases [1-4]. In this regard, within the framework of the generalization and requirements of the Ministry of Health standards, many standard indicators were combined that are regulated by the method of treatment and the quality of medical services and additional ones that regulate the quality of equipment operation and para-medical indicators. Also, it was taken into account that according to the form of presentation, indicators are divided into quantitative and qualitative. Let's designate the number of regulated indicators $\mathrm{P}$ to be measured at the request of the Ministry of Health together with additional K, the list of which is increased as necessary.

Let's represent the set of indicators $\mathrm{T}$ as a component vector $\bar{X}$. Let's suppose that for each of the indicators, the lower and upper boundaries of fluctuations in values and a verbal or fuzzy description in the form of membership functions in the range of parameter changes are determined:

$$
\mu_{j}\left(X_{j}\right)=f\left(X_{j}\right)
$$

Under these conditions, the total number of measurements of all parameters to be measured for $N$ regulated times at intermediate A grinding points of the analysis time interval will be equal to:

$$
M=(A+1)(K N+P N) .
$$

The latter, with the maximum bit depth of the values of the state parameters $Q$, determines the maximum required volumes of information $V$ to be transmitted during monitoring:

$$
V=Q M=Q(A+1)(K N+P N) .
$$

Thus, an excessive number of verbal and quantitative parameters, together with the effect of shredding the time measurement intervals, significantly increases the amount of information from transmission. Their reduction or loss significantly affects the error. In this regard, the determination of the justified value is an independent task of the information preprocessing algorithm, but which is not posed in this article. The limiting value of the required volumes of information $V$ according to (6) allows to calculate the compression ratio.

Thus, a list of types of parameters has been defined that determine the GIPS, the quality of medical services, the state of the MARD, which are quantitative and qualitative in terms of the forms of presentation. In other words, the list satisfies the generalized requirements, formulates the terms of reference for the design of the MARD. According to the requirements, the number of parameters is not limited.

The limitation is imposed only on the options for entering and editing the list of additional quantitative and qualitative parameters. The total amount of information must be able to transmit MARD, determine the temporal properties of the parameters, the maximum digit capacity, the frequency of measurements and the number of derivatives, as well as the limits of permissible fluctuations in the values of the quantities to be analyzed.

\section{2. Applicability of the model and the method of inte-} gral assessment of the set of indicators

The object of physiotherapy as such was considered, characterized by $\mathrm{K}$ indicators, which were formed on the basis of data on the time series. Let's assume that they characterize quantitative parameters, for example, pressure, pulse, motor activity and qualitative self-awareness, and so on. Let's suppose that the methodology for the unambiguous determination of indicators is regulated, that it was chosen according to the instructions of the Ministry of Health, and investigate the applicability of the model for the GIPS integrated assessment according to (5), including during the restoration.

To assess the influence of errors in measuring the parameters $\Delta X_{i}$ on the GIS, the process was considered as a non-direct measurement with a relative error $\varepsilon_{i}$, which made it possible to calculate:

$$
\Delta G I S=G I S \sum_{i=1}^{4}\left|\frac{\Delta X_{i}}{X_{i}}\right|=G I S \sum_{i=1}^{4}\left|\varepsilon_{i}\right| .
$$

By virtue of the selected norms, the maximum possible value of the error of the integral indicator is greater than the sum of the absolute values of the relative errors. To determine the influence of the value of the averaging interval and the dynamic properties of the GIS on the local value of the error, let's apply the quadratic Taylor series expansion in the vicinity of the time instant $t_{0}$ :

$$
\begin{aligned}
& \Delta G I S=\left(\begin{array}{l}
G I S_{0}+\left.\sum_{i=1}^{4} \frac{\partial G I S}{\partial X_{i}} \frac{d X_{i}}{d t}\right|_{t_{0}} \Delta t+ \\
+\left.\sum_{j=1, i=1}^{4,4} \frac{\partial^{2} G I S}{2 \partial X_{j} \partial X_{i}} \frac{\partial X_{j} \partial X_{i}}{d t^{2}}\right|_{t_{0}} \Delta t^{2}
\end{array}\right) \times \\
& \times \sum_{i=1}^{4}\left(\varepsilon_{i 0}+\left.\frac{d \varepsilon_{i}}{d t}\right|_{t_{0}} \Delta t+\left.\frac{d^{2} \varepsilon_{i}}{2 d t^{2}}\right|_{t_{0}} \Delta t^{2}\right) .
\end{aligned}
$$

Thus, the dynamic properties of the GIS, the averaging interval $\delta_{\tau}$, and the estimates of the error of the influencing factors formed the requirements for the maximum estimation time for each of the values of the indicators. Expansions (8) also made it possible to establish a general relationship between the dimensions of the slip window, the jumps of the first and second derivatives of the generalized time series, 
and the allowable GIS error. The applicability of decomposition (8), under the conditions of continuity and integrability of the GIS function together with the square, after applying the norm leads to the equation:

$$
\|\Delta G I S\|=\frac{1}{\delta \tau}\left[\int_{t_{0}-\delta \tau / 2}^{t_{0}+\delta \tau / 2} \Delta G I S^{2} \mathrm{~d} t\right]^{1 / 2} .
$$

Application of norm (9) to equation (8) gives, based on the Bunyakovsky-Cauchy inequality:

$$
\begin{aligned}
& \left|G I S_{0}+\frac{d G I S}{d t}\right|_{t_{0}} \Delta t+\left.\left.\frac{d^{2} G I S}{2 d t^{2}}\right|_{t_{0}} \Delta t^{2}\right|_{\min } \times \\
& \times \sum_{i=1}^{4}|| \varepsilon_{i 0}+\left.\frac{d \varepsilon_{i}}{d t}\right|_{t_{0}} \Delta t+\left.\frac{d^{2} \varepsilon_{i}}{2 d t^{2}}\right|_{t_{0}} \Delta t^{2}\|\leq\| \Delta G I E \| \leq \\
& \leq\left|G I S_{0}+\frac{d G I S}{d t}\right|_{t_{0}} \Delta t+\left.\left.\frac{d^{2} G I S}{2 d t^{2}}\right|_{t_{0}} \Delta t^{2}\right|_{\max } \times \\
& \times \sum_{i=1}^{4}\left\|\varepsilon_{i 0}+\left.\frac{d \varepsilon_{i}}{d t}\right|_{t_{0}} \Delta t+\left.\frac{d^{2} \varepsilon_{i}}{2 d t^{2}}\right|_{t_{0}} \Delta t^{2}\right\| \text {. }
\end{aligned}
$$

The last inequality is equivalent to an expression that defines the upper and lower bounds that limit the value of the norm of the relative error. It connects the error rate with the properties of the formed time series for the pessimistic GIS assessment and the length of the slip window.

$$
\begin{aligned}
& \left.\left.\left.|| G I S_{0}|+| \frac{d G I S}{d t}\right|_{t_{0}} \Delta t|+| \frac{d^{2} G I S}{2 d t^{2}}\right|_{t_{0}} \Delta t^{2}\right|_{\max } \\
& \times \sum_{i=1}^{4}\left|\varepsilon_{i 0}+\frac{d \varepsilon_{i}}{d t}\right|_{t_{0}}^{\Delta t+\left.\frac{d^{2} \varepsilon_{i}}{2 d t^{2}}\right|_{t_{0}} \Delta t^{2} \mid} \leq \\
& \leq \frac{\| \Delta G I S \mid}{\left|G I S_{0}\right|+\left.\left|\frac{d G I S}{d t}\right|_{t_{0}} \Delta t|+| \frac{d^{2} G I S}{2 d t^{2}}\right|_{t_{0}} \Delta t^{2}||_{\max }} \leq \\
& \leq \sum_{i=1}^{4}|| \varepsilon_{i 0}+\left.\frac{d \varepsilon_{i}}{d t}\right|_{t_{0}} ^{\Delta t+\left.\frac{d^{2} \varepsilon_{i}}{2 d t^{2}}\right|_{t_{0}}} \Delta t^{2} \mid .
\end{aligned}
$$

Thus, if the set of indicators to be measured and reflected for the work of each of the subjects of the family medicine system is a continuous set, then it is represented in metric space and time by means of normalization. The sequential selection and application of two types of Euclidean norms: the maximum modulus and combined for (1) and the square root of the integral of the square according to (9) forms a simple transparent reflection on an unlimited set of planes with a common axis - time.

Thus, based on the fundamental expansion of the function in a Taylor series and the geometric roughness, the model is multiplicative. Its features and properties are established on the basis of methods of weight coefficients, estimates of the upper and lower bounds, differentiation of the natural logarithm of the Bunyakovsky-Cauchy inequality. The very form of representing the value of the GIS as one number, and the dynamics in the form of a simple graph on a limited range of numbers from 0 to 1 , is the implementation of simplicity and transparency, as principles, in particular, PA. Taken together, it provides random access for the patient, family doctor, specialty doctor and administrators and implements another of the principles of accessibility.

\section{3. Applicability of the three-level vector-indicator for informational supplement of the time series is equal to parametric monitoring}

Let's consider the problem of analyzing changes in time series, obtained as a result of monitoring the parameters of the patient's condition. As a rule, oscillations are observed in them. Let's suppose that the series are not monotonic, but contain alternating intervals of monotonicity and low local minima and maxima. Such changes in the parameters of the patient's state and their models are impossible to study such series by the methods of Newton-Kantorovich and quasilinearization [26]. As shown in [13], the simultaneous use of several schemes of approximations and checks of the conditions for correspondence to the root at the point of each approximation excludes its erroneous determination. Numerical experiments for the above and other cases, in which the formation of the images contains several local extrema, indicate the impossibility of direct application of linear and quadratic approximation schemes. The latter is equivalent to the conclusion: the application of the Newton-Raphson-Kantorovich method, quasilinearization, Halley, recurrent approximation is impossible [27]. Due to the fact that most of the time series of the patient's state indicators are oscillating functions, the problem of the synthesis of the control action, as the problem of minimizing the quadratic functional, was not solved by these methods [13]. Modification and search for new approaches is a topical direction of research on ways to transform non-monotonic models [27].

Intellectualization of the process of finding the root. According to the two-level comparative idea [22], let's introduce a rule for the operation of a three-level comparator. Let there be a limited set of three values $Y_{1}, Y_{2}, Y_{3}$, on an unbounded space of real numbers $\forall Y \in(-\infty, \infty)$, then represent the comparator as such, realizing a predicate of the form:

$$
D_{1}\left(Y_{1}, Y_{2}, Y_{3}\right)= \begin{cases}-1, & \text { if } Y_{1 b}<Y<Y_{1}, \\ 0, & \text { if } Y=Y_{2}, \\ 1, & \text { if } Y>Y_{3}>Y_{3 e},\end{cases}
$$

where $Y_{1}, Y_{2}, Y_{3}$ - values of quantities taken as such, which are measured and are reference, the values of which will vary, and in some cases may be the same. Let's also assume that this rule (12) is valid for quantities of different nature, including derivatives of a quantity, suitable for measurement. Let's consider an oscillating process in the space of real numbers, shown in Fig. 1. Let's introduce an $n$-dimensional vector $\bar{V}$. The first component is the value of some physical quantity obtained after processing using the comparator (12). For simplicity, in this problem, all three values are assumed to be the same and equal to zero in (12). The second, third, and $n$-on components are, respectively, the first and second and $n-1$ of the derivative of a physical quantity, processed using the same comparator (12). Let's introduce an $n$-dimensional matrix row, each element of which is equal, respectively, to the magnitude of the modulus of the derivatives from the zero to the $n$-th order. Then the spread in the Taylor series is fed in the form 
of the product of this matrix by the square diagonal matrix $n \times n$ and the indicator vector of derivatives:

$$
\begin{aligned}
& L(x+\Delta)= \\
& =\left.\left[\left|L^{(0)}\right|,\left|L^{(1)}\right|, \ldots,\left|L^{(k)}\right|, . .\left|L^{(3)}\right|\right]\right|_{\substack{\Delta=0, x=x_{n}}}\left\|\frac{1}{k !}(\Delta)^{k}\right\| \bar{V} .
\end{aligned}
$$

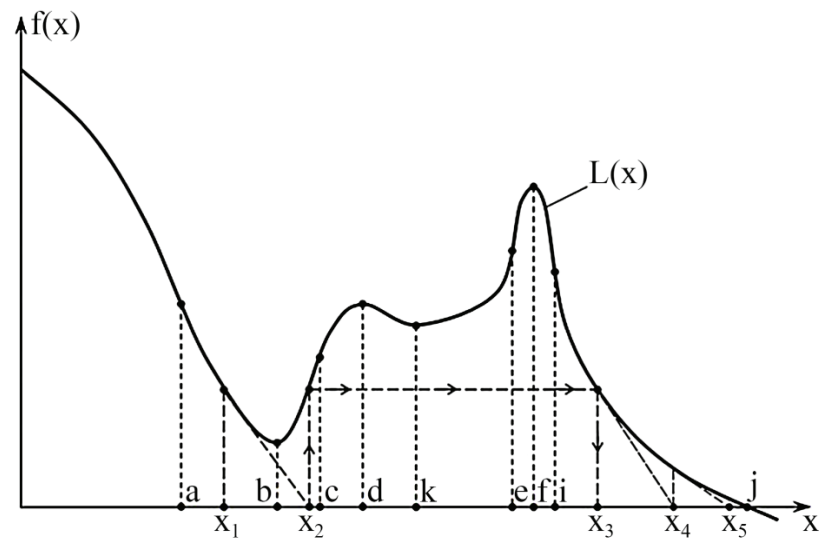

Fig. 1. Scheme of approximations and characteristic points for a non-monotonic function

The diagonal matrix is accepted for generality $0 !=1, k=j+1$. In this notation, the problem of finding a root is reduced to the problem of solving an equation with a vector-indicator

$$
\left.\left[\left|L^{(0)}\right|,\left|L^{(1)}\right|, \ldots,\left|L^{(k)}\right|, \ldots\left|L^{(N)}\right|\right]\right|_{\substack{\Delta=0, x=x_{n}}}\left\|\frac{1}{k !}(\Delta)^{k}\right\| \bar{V}=0 .
$$

The recovery dynamics process can be represented in matrix form in accordance with the approximation schemes:

- linear

$$
\left.\Delta\left[\left|L^{(0)}\right|,\left|L^{(1)}\right|, \ldots,\left|L^{(k)}\right|, . .\left|L^{(N)}\right|\right]\right|_{\substack{\Delta=0, x=x_{n}}}\left\|\frac{1}{k !}(\Delta)^{k-1}\right\| \bar{V}=0
$$

- quadratic

$$
\left.\Delta^{2}\left[\left|L^{(0)}\right|,\left|L^{(1)}\right|, \ldots,\left|L^{(k)}\right|, . .\left|L^{(N)}\right|\right]\right|_{\substack{\Delta=0, x=x_{n}}}\left\|\frac{1}{k !}(\Delta)^{k-2}\right\| \bar{V}=0 .
$$

If to restrict ourselves to only quadratic approximation, their solution can be written for the corresponding approximation schemes in the following way:

- for linear

$$
\Delta=-2 V_{1} V_{2}\left|L^{(0)}\right|\left|L^{(1)}\right| /\left[\begin{array}{c}
2\left(V_{2}\left|L^{(1)}\right|\right)^{2}- \\
-V_{1} V_{3}\left|L^{(0)}\right|\left|L^{(2)}\right|
\end{array}\right] ;
$$

- for quadratic

$$
\Delta=-\frac{V_{2}\left|L^{(1)}\right|}{V_{3}\left|L^{(2)}\right|}+\sqrt{\left[\frac{V_{2}\left|L^{(1)}\right|}{V_{3}\left|L^{(2)}\right|}\right]^{2}-\frac{2 V_{1}\left|L^{(0)}\right|}{V_{3}\left|L^{(2)}\right|}} .
$$

The process of non-monotonic dynamic changes of the model was considered. An example of non-monotonic dynamics of the model is shown in Fig. 1, on which characteristic points are highlighted and marked with letters. The value of the indicator vector for them is presented in Table 1. Analysis of the data in Table 1 shows when the recovery process should be stopped. So, for the first value $x_{1}$, if for any of the approximation schemes, $x_{2}$ is obtained, the vector-indicator of which is $(1,0,1)$ or $(1,1,0)$, the approximation process should be stopped and the procedure should be taken according to the following rules. First, suppose: $L\left(x_{3}\right)$. Find the point $x_{3}$, and then continue according to the usual approximation scheme.

Table 1

The magnitudes of the values of the components of the vector-indicator at the point

\begin{tabular}{|c|c|c|c|c|}
\hline \multirow{2}{*}{ Point } & \multicolumn{5}{|c|}{ The values of the components of the vector-indicator at } \\
\cline { 2 - 5 } the point
\end{tabular}

Using the points in Fig. 1 and Table 1 traces additional informational opportunities, formed due to the introduction of an vector-indicator and the study of the dynamics of recovery processes as a complex indicator by methods of mathematical analysis. Table 1 are presented for points $a, b, c, d$ as the values of the vector components of the indicator give an unambiguous imagination not only about the changes in the indicator at the point, but also about the predicted changes in its environment. So, for example, consider point a, the second column of Table 1 . The value of the GIS vector-indicator $(1,1,1)$ shows that the intended procedure acts positively and improves the patient's condition, and GIS $(1,0,1)$ warns a critical state, requires a thorough examination by a special doctor, while the review procedures are suspended. The latter is the intellectual foundation for analyzing the impact of the restoration procedure and justifies the tool for intelligent analysis of GIS properties.

5. 4. Tools of public administration in the software for monitoring, diagnostic conclusion and correction of the course of procedures

For simplicity and transparency of the problem statement in accordance with the implementation of the PA principles, let's assume that by the start of work, the server has sent data on the number of measurements $N$. By one dimension let's obtain the values of $K+P$ parameters $x_{k}(t)(k=1,2, \ldots 4)$, namely: pressure, pulse, motor activity and self-awareness, which is regulated for measurement. The parameters are measured after a certain time interval $\Delta t$ in connection with the application of the expansion of each function $x_{k}(t)(k=1,2, \ldots 4)$ in a Taylor series in the form:

$$
x_{k}(t)=x_{k}\left(t_{0}\right)+\frac{x_{k}^{\prime}\left(t_{0}\right)}{1 !} \Delta t+\frac{x_{k}^{\prime \prime}\left(t_{0}\right)}{2 !} \Delta t^{2} .
$$

To obtain the value $\mathrm{x}_{k}\left(t_{0}\right)$, it is necessary to carry out measurements at the moment of time $t=t_{0}$. To obtain the value of the derivative, it is necessary to obtain the values of all parameters $x_{k}(t)(k=1,2, \ldots 4)$ at two points with a time interval $\Delta t$. Then the derivative is calculated as the ratio of 
the increment of the function $x_{k}(t)$ to the increment of the argument $\Delta t$, which caused it, provided that the increment of the argument tends to 0.

$$
\begin{aligned}
& \Delta x_{k}(t)=x_{k}\left(t_{0}+\Delta t\right)-x_{k}\left(t_{0}\right), \\
& x_{k}^{\prime}(t)=\frac{\Delta x_{k}(t)}{\Delta t}(\text { at } \Delta t \rightarrow 0) .
\end{aligned}
$$

Accordingly, to obtain the second derivative, it is necessary to obtain the values of the parameters at three points. Having calculated the value of the first derivative for the parameters $x_{k}(t) \quad(k=1,2,4)$ at the first and second and second and third points, let's obtain the second derivative as the ratio of the increment of the first derivative to the increment of the argument $\Delta t$, which tends to 0

That is:

$$
\begin{aligned}
& \Delta x_{k}^{\prime}(t)= \\
& =x_{k}^{\prime}\left(t_{0}+\Delta t\right)-x_{k}^{\prime}\left(t_{0}\right), \\
& x_{k}^{\prime \prime}(t)= \\
& =\frac{\Delta x_{k}^{\prime}(t)}{\Delta t}(\text { at } \Delta t \rightarrow 0) .
\end{aligned}
$$

Accordingly, to obtain the third derivative, it is necessary to have the values of the parameters $x_{k}(t)$ $(k=1,2, \ldots 4)$ at four points, etc.) $(k=1,2 \ldots 4)$ at $n$ points with a constant time step $\Delta t$.

For the formation of imagination and further discussion of the monitoring algorithm for a diagnostic conclusion and correction of the course of procedures, its block diagram is shown in Fig. 2. The number of points $(A)$ for each measurement is set from the server and the interval of grinding time between measurements at two points $(\Delta t)$ is selected. In addition, it is also necessary to know the start time and end time of all $N$ measurements $\left(t_{1}, t_{N}\right)$.

The next step is to find the interval between $N$ measurements $\Delta T$

$$
\Delta T=\frac{\left(t_{N}-t_{1}\right)}{N}-A^{*} \Delta t
$$

To start the countdown at the current time $t$, the initial moment $t_{1}$ is assigned, and the accountant of the number of situations (calc), when the value of at least one of the parameters $\left(x_{1}(t), x_{2}(t), x_{3}(t)\right.$, $\left.x_{4}(t)\right)$ goes beyond set limits, set equal to zero.

Let's start a cycle from 1 to $N$ with a step of 1 , to carry out $N$ measurement sessions. Thus, at each step of the simulation, there is a cycle of obtaining the values of the parameters $x_{k}(t)$ $(k=1,2, \ldots 4)$ for the number of points $A$ with a time step $\Delta t$.

Therefore, inside this cycle, let's start a new cycle $j$ from 1 to $A$ with step 1 . Then let's denote the parameters $x_{k i j}(t)$ $(k=\overline{1,4}, i=\overline{1, N}, j=\overline{1, A})$ with a time interval $\Delta t$. After one cycle of measurements at $A$ points with a time interval $\Delta t$, the integral indicator $G I S_{i j}(t)$ is calculated.

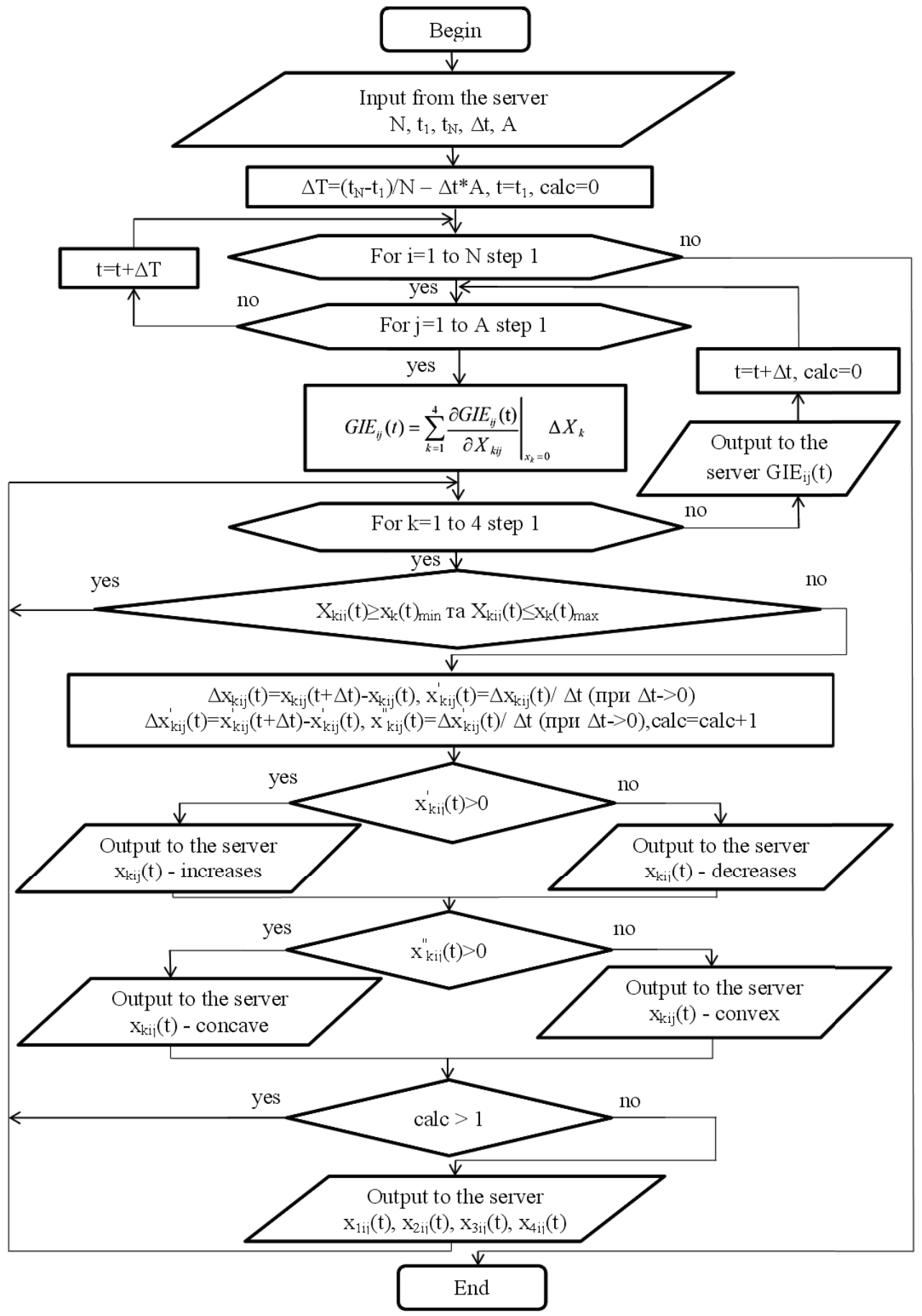

Fig. 2. Block diagram of the monitoring algorithm for the diagnostic conclusion and correction of the course of procedures 
The next step in cycle $k$ from 1 to $4 \mathrm{~s}$ with step 1 is to check each parameter for belonging to the range of values corresponding to the patient's normal state for this parameter.

If the parameter $x_{k i j}(t)(k=1,2, \ldots 4)$ does not meet the requirements, since the deviation reaches a value greater than the norm, the values of the first and second derivatives $x_{k i j}^{\prime}(t), x_{k i j}^{\prime \prime}(t)$ are subtracted) to check the nature of changes in the function $x_{k i j}(t)$. This data is sent to the server. The calc counter increases the value by 1 and sends the values of all parameters $x_{k i j}(t)(k=1,2, \ldots 4)$ to the server (if calc exceeds 1 , if one of the parameters does not meet the requirements, the data will not be sent to the server again sent).

When all checks are passed or after the end of the cycle ( $k$ runs through values from 1 to 4 with a step of 1 ), only the value of the integral indicator $G I S_{i j}(t)$ is sent to the server. After the calc value is reset to zero, the time is increased by $\Delta t$ and the transition to the next measurement point of cycle $j$ runs through the values from 1 to $A$ with increments of 1 .

After the end of the series of measurements, the time interval is increased by $\Delta T$ and the transition to the next step in the cycle and from 1 to $N$ with step 1 . After the end of this cycle, the program ends.

The presentation of GIPS data in numerical, qualitative or graphical form in a single metric space makes the data easy to understand, accessible to all PA subjects. Simulations were carried out to determine the GIPS applicability to the compression of information volumes. To compare the efficiency of the GIPS model, when the digits are represented by eight digits of the binary number system, an experiment was carried out to determine the volumes to be transferred. The results of the experiment are presented in Table 2.

Table 2

Amounts of transferred information

\begin{tabular}{|c|c|c|c|c|c|c|}
\hline \multirow{2}{*}{ No. } & \multicolumn{2}{|c|}{$\begin{array}{c}\text { Ten } \\
\text { measurements }\end{array}$} & \multicolumn{2}{c|}{$\begin{array}{c}\text { Twenty } \\
\text { measurements }\end{array}$} & \multicolumn{2}{c|}{ A measurements } \\
\cline { 2 - 7 } & $\begin{array}{c}\text { Amount } \\
\text { of infor- } \\
\text { mation, } \\
\text { bytes }\end{array}$ & $\begin{array}{c}\text { Com- } \\
\text { pression } \\
\text { ratio }\end{array}$ & $\begin{array}{c}\text { Amount } \\
\text { of infor- } \\
\text { mation, } \\
\text { bytes }\end{array}$ & $\begin{array}{c}\text { Com- } \\
\text { pression } \\
\text { ratio }\end{array}$ & $\begin{array}{c}\text { Amount } \\
\text { of infor- } \\
\text { mation, } \\
\text { bytes }\end{array}$ & $\begin{array}{c}\text { Compression } \\
\text { ratio }\end{array}$ \\
\hline 1 & 40 & 0.75 & 80 & 0.75 & $4 \mathrm{~A}$ & $1-\mathrm{A} /(4 \mathrm{~A})$ \\
\hline 2 & 56 & 0.536 & 96 & 0.625 & $4 \mathrm{~A}+16$ & $1-\mathrm{A} /(4 \mathrm{~A}+16)$ \\
\hline 3 & 60 & 0.500 & 100 & 0.600 & $4 \mathrm{~A}+20$ & $1-\mathrm{A} /(4 \mathrm{~A}+20)$ \\
\hline
\end{tabular}

During the experiment, according to the described algorithm, it was assumed that four parameters were outside the range of acceptable values. Also, the number of measurement points for which the data is presented in the table is equal to 10 and 20. Experience shows that the introduction of the GIPS model significantly reduces the total amount of data that must be transferred to the server.

\section{Discussion of the results of the study of the list of parameters, application of the integral indicator model, vector-indicator, analysis tools}

In the course of the study, it was found that the formed list of parameters of the patient's condition, which are regulated by the Ministry of Health standard and the list of metrologically substantiated indicators for monitoring the quality of medical care, there are contradictions. The proposed model, the form of which is substantiated on the basis of reducing to one metric space of one interval of definition and values and applying a generalized geometric roughness, does not eliminate the problem of contradictions, but brings the system under the same comparison conditions. So, by determining the integral indicator taking into account the weight coefficients, it was previously sequentially processed by the Euclidean norms (1), the expediency of using a pessimistic assessment is substantiated, which is not affected by the number of parameters. Thus, as shown for such an assessment, the number of indicators may not be limited to four. This result is explained by the fact that the parameters define one object, and the series expansion of the function of many variables, regardless of their number, satisfies (2). In connection with the linear form of the series expansion (2) and geometric inequality (3), it is determined by their dual function - the integral indicator. In addition, as (8) shows, the error in determining the integral indicator does not depend on the number of indicators, but is determined only by their properties, such as jumps of derivatives and the size of the slip window (10), (11).

Thus, in the conditions of the available possibilities to regulate the size of the sliding window, its value should be chosen taking into account the jumps of the first and second derivatives of the generalized time series and the permissible error. When using qualitative indicators determined on the basis of cognitive testing, they must be reduced to normalized membership functions. Further, such normalization opens up the possibility of constructing a GIPS according to algorithm (3), for which (6), (7) are carried out as estimates of the forecast accuracy.

Table 2 shows the amount of information for different numbers of measurements and for a different number of points. So, to calculate the second derivative, more data on four components at four points is added - the second line. The third line adds data on four components at four points for calculating the third derivative and the fifth for calculating the predicted point. Analysis of the data shows that the use of the GIPS significantly compresses the amount of information transmitted by seventy-five percent reduced, and the compression ratio does not depend on the number of measurement points. It depends on the properties of the time series. As shown in [9], the need to measure a larger number of points is caused by the need to improve the accuracy of the information forecast. So, to calculate the first, second and third derivatives, four points are needed, and the fifth point is to check the predicted value. The latter decreases the value of the compression ratio, which, with an increase in the number of measurements, grows and tends to the limiting values. The value of the limiting value of the compression ratio is determined by the number of indicators of the patient's condition.

This study, in contrast to previous studies [12], not only offers a tool for analyzing the time series, but also, in contrast to [17], also substantiates the tool for the intellectual analysis of oscillating time series characterizing the recovery processes. However, the more important difference between the proposed method of forming an integral indicator is the ability to assess verbal paramedical indicators. The presented results of the analysis definitely did not cover all cases of real features of the origin of the data, since it was artificially assigned at this stage of the study that all data are reliable, and the relative error is known. However, of course, the GIPS model, as an aggregate indicator based on groups of quantitative and qualitative indicators, must be verified on 
the data during the implementation of the MARD, which requires further research.

Thus, the choice of points at which it is sufficient to transfer not a complete set of data, but only the value of the GIPS, depends on the properties of the time series of parameters. The latter will determine, together with the parameters of the measurement accuracy and the required data accuracy, the preprocessing algorithm, which will affect the data compression ratio. Thus, the work continued the implementation of the idea of calibrating the channels of devices [27], which measure oscillating quantities. The generated method and the algorithm and software built on its basis, the block diagram of which is shown in Fig. 2, is bounded by the space of real positive numbers, due to the Maclaurin series expansion and geometric inequality.

The disadvantages include the need to carry out normalization when jumping norms between measurement intervals, increases the amount of additional calculations when searching for auxiliary values, values of derivatives, components of the vector-indicator.

However, additional application of their results allows building GIPS on the basis of quantitative and qualitative indicators. Graphical and numerical presentation of observation results in the form of a single GIPS, which carries information about the dynamics of the course of recovery processes, ensures the implementation of administrative law and PA principles. The further direction of the development of these ideas is associated with the implementation of single-chip and single-board controllers, Wi-Fi systems of recovery devices, partially eliminating the problems of calculating derivatives and the vector-indicator and requires further experimental research.

\section{Conclusions}

1. A list of types of parameters has been formed, which include indicators of the general condition of the patient, it is recommended by the list of the Ministry of Health of this group of diseases, the quality of medical services, paramedical, the state of equipment, presented quantitatively or qualitatively. All indicators are reduced to the metric space of a limited interval, by sequentially entering two norms. The amount of information for transmission determines the time frequency of the measurement according to the method of the Ministry of Health, the number of interval refinements, the number of derivatives, the limits of permissible fluctuations in the values of their values and the maximum permissible digit capacity.

2. The GIPS model, as the lower bound of the linear expansion in the Maclaurin series, is a pessimistic estimate that does not depend on the number of indicators if they are preliminarily reduced to the metric space of a bounded interval by applying two norms. GIPS, presented by MARD in the form of a time series for post-infarction, post-stroke patients, corresponds to the principles of PA transparency, comprehensibility, accessibility, which are implemented in practice due to their tools. The sequence of applied actions for the formation of assumptions, norms, the determination of the weight coefficients is a method that justifies the value of the lower limit and can be extended to other types of sets describing one object to determine the generalized indicator.

3. The vector-indicator, built using a three-level comparator, forms a tool for intelligent analysis of GIPS properties and building logical rules for informational supplement of the time series of one-parameter monitoring. So, the value of the vector indicator of the GIPS $(1,1,1)$ shows that the intended procedure acts positively and improves the patient's condition, and the GIPS $(1,0,1)$ warns of a critical condition, requires a thorough examination by a special doctor, the review procedures are suspended.

4. Presentation of data in the form of GIPS time series and additional materials at selected points is easily applied in software and is a transparent tool of administrative law and evidence-based medicine. The value of the compression ratio with an increase in the number of measurements grows and tends to the limit values up to $60-75 \%$ for eight digits of the binary number system and four indicators, which is determined by the number of indicators of the patient's condition. The properties of the GIPS model, a vector-indicator that are convenient for building analysis algorithms, form a tool for managing the amount of information and sorting into a protected one and such that it is presented as transparent, understandable and accessible, which corresponds to the PA principles.

\section{References}

1. Pro reabilitatsiyu u sferi okhorony zdorovia. Stattia 19. Nadannia reabilitatsiynoi dopomohy iz zastosuvanniam telereabilitatsiyi (2021). Verkhovna Rada Ukrainy, 8. Available at: https://zakon.rada.gov.ua/laws/show/1053-20\#Text

2. U 2020 rotsi likuvannia hostroho mozkovoho insultu ye priorytetom v prohrami medychnykh harantiy. Ministerstvo okhorony zdorovia Ukrainy (2019). Available at: https://www.kmu.gov.ua/news/u-2020-roci-likuvannya-gostrogo-mozkovogo-insultu-yeprioritetom-v-programi-medichnih-garantij

3. Unifikovanyi klinichnyi protokol medychnoi dopomohy. Ishemichnyi insult (ekstrena, pervynna, vtorynna (spetsializovana) medychna dopomoha, medychna reabilitatsiya). Zatverdzheno. Nakaz Ministerstva okhorony zdorovia 03.08.2012 No. 602. Available at: https://dec.gov.ua/wp-content/uploads/images/dodatki/2012_602/2012_602dod4ykpmd.pdf

4. Pro zatverdzhennia indykatoriv yakosti medychnoi dopomohy. Nakaz MOZ Ukrainy vid 02.11.2011r. No. 743. Verkhovna Rada Ukrainy. Available at: https://zakon.rada.gov.ua/laws/show/z1328-11\#Text

5. Yakovleva, O. G. (2019). Main ways of formation and development of family medicine in Ukraine as the basis of reorganization of primary medical and sanitary aid for population. Nursing, 2, 16-21. doi: https://doi.org/10.11603/2411-1597.2019.2.10192

6. Steel, A., Sibbritt, D., Schloss, J., Wardle, J., Leach, M., Diezel, H., Adams, J. (2017). An Overview of the Practitioner Research and Collaboration Initiative (PRACI): a practice-based research network for complementary medicine. BMC Complementary and Alternative Medicine, 17 (1). doi: https://doi.org/10.1186/s12906-017-1609-3

7. Pro zatverdzhennia Kontseptsiyi upravlinnia yakistiu medychnoi dopomohy u haluzi okhorony zdorovia v Ukraini na period do 2020 roku. Nakaz MOZ Ukrainy vid 01.08.2011 No. 454. Verkhovna Rada Ukrainy. Available at: https://zakon.rada.gov.ua/rada/ show/v0454282-11\#Text 
8. Stallberg, B., Teixeira, P., Blom, C., Lisspers, K., Tsiligianni, I., Jordan, R. et. al. (2016). The prevalence of comorbidities in COPD patients and their impact on quality of life and COPD symptoms in primary care patients - An UNLOCK study from the IPCRG. 1.6 General Practice and Primary Care. doi: https://doi.org/10.1183/13993003.congress-2016.pa868

9. Nahorna, A. M. (2003). Sotsialno-ekonomichni determinanty zdorovia naselennia Ukrainy (ohliad literatury i vlasnykh doslidzhen). Zhurnal AMN Ukrainy, 9 (2), 325-345.

10. Hoida, N. H., Horachuk, V. V. (2011). Medyko-sotsiolohichna informatsiya yak instrument upravlinnia yakistiu medychnoi dopomohy. Tezy dopovidei konferentsiyi z mizhnarodnoiu uchastiu «Medychna ta biolohichna informatyka ta kibernetyka: vikhy rozvytku». Kyiv, 27.

11. Melnykova, N. (2014). The features of decision making quality evaluation in medicine. Visnyk Natsionalnoho universytetu «Lvivska politekhnika», 805, 170-179. Available at: http://science.lpnu.ua/sisn/all-volumes-and-issues/volume-805-2014/ osoblivosti-ocinyuvannya-yakosti-rezultativ-priynyattya

12. Shchelkalin, V. (2015). A systematic approach to the synthesis of forecasting mathematical models for interrelated non-stationary time series. Eastern-European Journal of Enterprise Technologies, 2 (4 (74)), 21-35. doi: https://doi.org/10.15587/1729-4061.2015.40065

13. Trunov, A. (2017). Recurrent Approximation in the Tasks of the Neural Network Synthesis for the Control of Process of Phototherapy. Computer Systems Healthcare and Medicine. Denmark, 213-248.

14. The Ultimate Comparison of IOT Development Boards (2013). Open Electronics. Available at: https://www.open-electronics.org/ the-ultimate-comparison-of-iot-development-boards/

15. Tymoshchuk, P. V., Shatnyi, S. V. (2012). Systema monitorynhu ta keruvannia viddalenymy obiektamy rehuliuvannia. Naukovyi visnyk NLTU Ukrainy, 22, 313-318.

16. Shatnyi, S., Shatna, A., Shablovska, A. (2019). Neural Network Hardware Implementation Using Micro- and Softprocessor Technologies for Biomedical Signal Processing. International Journal of Advanced Research in Computer Engineering \& Technology (IJARCET), 8 (8), 400-403. Available at: http://ijarcet.org/wp-content/uploads/IJARCET-VOL-8-ISSUE-8-400-403.pdf

17. Trunov, A., Beglytsia, V. (2019). Synthesis of a trend's integral estimate based on a totality of indicators for a time series data. Eastern-European Journal of Enterprise Technologies, 2 (4 (98)), 48-56. doi: https://doi.org/10.15587/1729-4061.2019.163922

18. Mishchuk, O. (2019). Development of the method of forecasting the atmospheric air pollution parameters based on error correction by neural-like structures of the model of successive geometric transformations. Technology Audit and Production Reserves, 6 (2 (50)), 26-30. doi: https://doi.org/10.15587/2312-8372.2019.188743

19. Mishchuk, O., Tkachenko, R., Pohrebennyk, V. (2019). The Accelerated Method of Filling Gaps in Data Using a Linear SGTM Neural-Like Structure. International Journal of Science and Engineering Investigations (IJSEI), 8 (91), 154-159. Available at: http://www.ijsei.com/papers/ijsei-89119-20.pdf

20. Kovalchuk, A. M., Levytskyi, V. H. (2002). Rozrobka adaptyvnoho interfeisu korystuvacha prohramnoi systemy chyselnoho analizu matematychnykh zadach. Visnyk ZhITI, 20, 111-119.

21. Bias, R.; Nielsen, J., Mack, R. (Eds.) (1994). The Pluralistic Usability Walkthrough: Coordinated Empathies. Usability Inspection Methods. John Wiley.

22. Petrov, K. E., Kryuchkovskiy, V. V. (2009). Komparatornaya strukturno-parametricheskaya identifikatsiya modeley skalyarnogo mnogofaktornogo otsenivaniya. Kherson: Oldi-plyus, 294.

23. Fisun, M., Smith, W., Trunov, A. (2017). The vector rotor as instrument of image segmentation for sensors of automated system of technological control. 2017 12th International Scientific and Technical Conference on Computer Sciences and Information Technologies (CSIT). doi: https://doi.org/10.1109/stc-csit.2017.8098828

24. Boichenko, O. V. (2012). Osnovni pryntsypy proektuvannia yakisnoho prohramnoho zabezpechennia avtomatyzovanykh system upravlinnia. Measurement and computation technique in technological processes, 3, 88-91. Available at: https://journals.khnu.km.ua/ index.php/MeasComp/article/view/1725/2191

25. Horachuk, V. V. (2012). Upravlinnia yakistiu medychnoi dopomohy v zakladi okhorony zdorovia. Vinnytsia: PP Baliuk I.B., 18-23.

26. Bellman, R. E., Kalaba, R. E. (1965). Quasilinearization and nonlinear boundary-value problems. American Elsevier Publishing Company.

27. Trunov, A., Malcheniuk, A. (2018). Recurrent network as a tool for calibration in automated systems and interactive simulators. Eastern-European Journal of Enterprise Technologies, 2 (9 (92)), 54-60. doi: https://doi.org/10.15587/1729-4061.2018.126498 